\title{
Política de Acesso à Informaç̧ão nas Capitais Nordestinas: Análise do cumprimento da LAl pelo Poder Executivo Municipal
}

\section{Access to Information Policy in Northeastern Capitals: Analysis of LAl compliance by the Municipal Executive Branch}

\author{
Jovino Pinto Filho Mestrando em Administração Pública. Universidade Federal de Alagoas (UFAL) - Brasil. \\ jovinoadm@gmail.com \\ Luciana Peixoto Santa Rita Doutora em Administração. Universidade Federal de Alagoas (UFAL) - Brasil. \\ lupsantarita@gmail.com. \\ Ibsen Mateus Bittencourt Santana Pinto Doutor em Administração de Empresas. Universidade Federal de Alagoas (UFAL) - Brasil. \\ ibsen.ead@gmail.com
}

\section{RESUMO}

Esta pesquisa teve o objetivo de verificar se o Poder Executivo das capitais nordestinas cumprem a Lei de Acesso à Informação em seus sítios virtuais. O método utilizado foi quanti-qualitativo com desígnio exploratório-descritivo, por meio de investigação documental e pesquisa bibliográfica, tendo como instrumento um formulário de observação com os requisitos determinados pela lei. A coleta de dados ocorreu nos sítios virtuais das prefeituras e os dados foram submetidos à análise documental. Os resultados encontrados apontam que sete das nove prefeituras pesquisadas cumprem, eficientemente, mais da metade dos requisitos estabelecidos pela $\mathrm{LAl}$; tendo como principal dificuldade o agrupamento de requisitos referente à formatação dos sítios virtuais, com apenas dois dos oito itens tendo sido cumpridos plenamente pela maioria das capitais; quanto aos requisitos de transparência passiva, regulamentação e prestação de contas, cinco dos sete itens estavam em conformidade com a lei na maioria dos sítios pesquisados. Diante dos resultados, podese inferir que os sítios virtuais estão em conformidade com a maioria dos requisitos elencados pela LAI, respondendo positivamente a questão da pesquisa, contudo, para que haja maior conformidade à lei recomenda-se maior atenção à organização, segurança, integridade e acessibilidade dos sítios virtuais; dispor informações em formatos não proprietários, abertos e legíveis por máquina; e que disponham de clareza e concisão suficiente para promover condições de inferability aos cidadãos que buscam acesso às informações de seu interesse.

Palavras-chave: Lei n 12.527/2011. LAl. Acesso à Informação. Transparência. Capitais Nordestinas.

\begin{abstract}
The general objective of this research was to verify whether the executive power of the northeastern capitals comply with the Law on Access to Information ( $\mathrm{LAl}$ in their virtual sites. The method used was quantitative and qualitative with exploratory-descriptive design, through documentary research and bibliographic research, having as an instrument an observation form with the requirements determined by law. The data collection took place in the virtual sites of the city hall and the data were submitted to documentary analysis. The results found indicate that: seven of the nine municipalities surveyed efficiently meet more than half of the requirements established by the law for access to information; having as main difficulty the grouping of requirements related to the formatting of virtual sites, with only two of the eight items having been fully met by most capitals; as to passive transparency, legal regulation and accountability requirements, five of the seven items were in compliance with the law on most of the sites surveyed. In view of the results, it can be inferred that the virtual sites are in compliance with most of the requirements listed by LAl, responding positively to the research question. However, for greater compliance with the law, greater attention should be paid to the organization, security, integrity and accessibility of virtual sites; have information in non-proprietary, open and machine-readable formats; and with sufficient clarity and conciseness to promote conditions of inference to citizens seeking access to information of interest.
\end{abstract}

Keywords: Law no. 12.527/2011. LAI. Access to Information. Transparency. Northeastern Capitals. 


\section{INTRODUÇÃO}

O acesso à informação é um direito de todo cidadão, o qual está relacionado ao direito de liberdade de expressão e autonomia. A implementação deste direito pelo Estado é tema recorrente no meio acadêmico e social, e sua relevância é demonstrada, há vários anos, por estudos, legislações e convenções internacionais, como, por exemplo, a Declaração Universal de Direitos Humanos, da Organização das Nações Unidas (ONU) que, em 1948, defendeu o livre fluxo de informações em seu artigo 19, o qual apregoa que:

Todo o homem tem direito à liberdade de opinião e expressão; este direito inclui a liberdade de, sem interferências, ter opiniões e de procurar, receber e transmitir informações e ideias por quaisquer meios, independentemente de fronteiras (ONU, 1948, p. 10).

No Brasil, o direito à informação está expresso em sua Constituição, a qual expressa por meio de seu artigo 50, inciso XXXIII, que todos têm direito a receber dos órgãos públicos informações de seu interesse particular, ou de interesse coletivo, que serão prestadas no prazo da lei, sob pena de responsabilidade, ressalvadas aquelas cujo sigilo seja imprescindível à segurança da sociedade e do Estado (BRASIL, 1988).

Este dispositivo constitucional foi regulamentado, após mais de vinte anos, por meio da Lei 12.527/2011 - Lei de Acesso à Informação (LAl), e pelo Decreto no 7.724/2012. Sua construção foi fundamentada em parâmetros de acesso à informação internacionalmente reconhecidos, que trouxe ao arcabouço legislativo nacional conceitos que promovem maior compreensão quanto ao princípio da publicidade e da transparência (PAES, 2011).

Observa-se que o Brasil, no período ulterior à promulgação de sua Carta Magna, passou a criar uma série de mecanismos legais com o objetivo de promover a transparência como regra em suas ações, como se observa ao promulgar a Convenção das Nações Unidas contra a Corrupção, por meio do Decreto n 5687/2006, que tem a transparência como fator necessário para evitar a corrupção. Outras leis também foram sancionadas, tais como a Lei de Responsabilidade Fiscal (LRF); Decreto Federal no 6.170/2007, que instituiu o Sistema de Gestão de Convênios e Contratos de Repasse (SICONV); Lei Complementar no 131/2009 - Lei da Transparência; Lei 13.460/2017, que prevê em seu art. $7^{\circ}$ a elaboração e divulgação da Carta de Serviços ao Usuário, para informá-lo dos serviços prestados pelo órgão ou entidade públicos (AMORIM; STADLER, 2019). Comportamento distinto do que ocorria na fase patrimonialista da administração brasileira, na qual a informação era circunscrita a poucos e direcionada a interesses privados, favorecendo a corrupção e o consequente descrédito do Estado (ROSA et al., 2016).

Para que ocorra a transparência, as informações precisam estar disponibilizadas de forma que possam ser localizadas facilmente, com agilidade, em formato passível de verificação, linguagem clara e compreensível (DREHMER; RAUPP, 2018). Faz-se necessário, então, estabelecer regulamentos que determinem aos órgãos públicos o provimento de informações de forma padronizada. Nesse sentido, a legislação que trata a respeito do acesso às informações podem ser encaradas como propulsoras para o aumento da transparência pública.

Importa frisar que a transparência é requisito essencial para o exercício da participação popular, para o controle social e para a accountability. No entendimento de Bitencourt e Reck (2016), a participação popular ocorre na interação da sociedade com a esfera pública, no momento de tomada de decisão pela Administração, enquanto o controle social ocorre após esse processo, quando a sociedade avalia se as decisões tomadas se concretizaram de acordo com o estabelecido. Por conseguinte, a accountability pode ser entendida como responsabilização dos governantes, ou seja, o processo ocorrido em sistemas democráticos que, institucionalmente, constrange os governantes à prestar contas de seus atos e omissões ao povo, tanto perante às eleições quanto ao longo de seu mandato (ABRUCIO; LOUREIRO, 2004).

No Brasil, a accountability é um processo em desenvolvimento, ainda não sendo possível afirmar se as forças que incentivam a democracia conseguirão sobrepor às que se baseiam no atraso, contudo, acreditase que mecanismos de transparência, prestação de contas e participação popular contribuam nesta construção (RAUPP, 2011). Nesse sentido, é indispensável que os cidadãos saibam de suas obrigações sociais e participem de forma efetiva das atividades de escolha de governantes, bem como vigiem continuamente suas ações e demandem as informações necessárias, afinal, sem a participação e controle social a responsabilização dos gestores públicos se inviabiliza (ROCHA, 2011). 
Diante das assertivas apresentadas, o presente estudo parte do seguinte questionamento: Há o cumprimento da Lei de Acesso à Informação pelo Poder Executivo das capitais nordestinas? Para responder essa questão, a pesquisa vem com o escopo de verificar se o Poder Executivo das capitais de estados do nordeste brasileiro cumprem a Lei de Acesso à Informação em seus sítios virtuais. Como objetivos específicos, o estudo buscou verificar se os sítios virtuais atendem ao rol de informações mínimas, caracterizados como transparência ativa; identificar se os sítios virtuais cumprem os requisitos de configuração, acessibilidade e ferramentas exigidos em lei; verificar se as capitais estão cumprindo os requisitos de transparência passiva, regulamentação e prestação de contas; bem como propor sugestões para resolução dos óbices encontrados.

Ao atingir os objetivos propostos, o estudo demonstra relevância por apresentar à sociedade, a avaliação de conformidade e possíveis falhas no que se refere à implementação das prerrogativas da LAl, bem como contribui para incentivar às gestões municipais a aprimorarem sua política de acesso à informação no intuito de garantir a efetividade deste direito do cidadão.

O artigo está dividido em quatro capítulos, além desta introdução. O segundo capítulo é subdivido em duas partes, as quais apresentam os aspectos teóricos e conceituais sobre transparência e sobre a Lei de Acesso à Informação. Logo após, o terceiro capítulo expõe os procedimentos metodológicos e instrumentos utilizados para o alcance dos objetivos estabelecidos. Já no quarto capítulo são apresentados os principais resultados da pesquisa, demonstrando o cumprimento da Lei de Acesso à Informação pelos sítios virtuais das prefeituras municipais de capitais dos estados nordestinos. Por fim, o capítulo cinco, expressa a análise dos dados e o alcance dos objetivos específicos como considerações finais do estudo.

\section{REVISÃO TEÓRICA}

Este capítulo apresenta e discute as teorias que subsidiam a construção da pesquisa e a análise dos resultados alcançados. Considerando-se que o presente artigo tem como objetivo verificar se o Poder Executivo das capitais do nordeste brasileiro cumprem a Lei de Acesso à Informação nos sítios virtuais de informações da prefeitura municipal, a revisão da literatura abrange conceitos relacionados à transparência no setor público, que é uma das consequências almejadas pela Lei n 12.527/2011, bem como, logo após, versa sobre a referida lei, abordando seus objetivos, benefícios e suas exigências aos órgãos e entidades do poder público.

\subsection{Transparência}

O debate sobre transparência, nos últimos anos, tem conseguido obter destaque tanto na opinião pública quanto nos meios acadêmicos, sendo um termo costumeiramente usado como sinônimo de solução para problemas existentes na conjuntura democrática (ZUCCOLOTTO; TEIXEIRA; RICCIO, 2015).

De acordo com Stiglitz (1999), transparência significa a redução das assimetrias de informações que ocorrem entre cidadãos e agentes estatais, de forma que facilitem a redução das falhas de gestão e permitam o controle social sobre os atos ilícitos cometidos no Estado, portanto, o público é capaz de avaliar melhor o valor adicionado pela ação pública. Para isso, a transparência deve demonstrar todas as ações dos gestores públicos, de forma que os cidadãos possam ter acesso e compreendam o que está sendo realizado por eles após o poder de representação que lhes foi confiado (CRUZ; SILVA; SANTOS, 2009).

A transparência tem como objetivo garantir a cada cidadão interessado o acesso às informações que possibilitem verificar o desempenho dos governantes, as ações em andamento, as que foram executadas em períodos anteriores, bem como as que estão em fase de planejamento (VISENTINI; SANTOS, 2019). Ainda de acordo com Visentini e Santos (2019), para alcançar este objetivo, a administração pública deve promover ampla divulgação, em meios eletrônicos ou audiências públicas.

É importante frisar que transparência pública não se confunde com o princípio da publicidade pois esta é satisfeita com a publicação dos atos do poder público em canais oficiais exigidos por lei, enquanto aquela é mais exigente, sendo percebida por meio uma atitude comportamental em relação ao outro, ou seja, é permitir a visibilidade e o desnudamento da gestão pública (GOMES FILHO, 2005). 
A esse respeito, Michener e Bersch (2011) apontam que a transparência se efetiva por meio de duas condições: visibility e inferability. A visibility (visibilidade) seria a predisposição do fornecedor de informações em dispô-las de forma completa acessível, pois estar visível não significa, necessariamente, que esteja fácil de ser encontrada. Por sua vez, inferability (capacidade de inferência) pressupõe até que ponto as informações disponíveis podem ser usadas para tirar conclusões com precisão, o que envolve sua qualidade e capacidade de usabilidade.

A respeito da inferability, Michener e Bersch (2011) destacam a questão da mediação dos dados como uma dimensão crítica pois, ao mesmo tempo que objetiva facilitar o entendimento da sociedade a respeito de determinadas informações, também pode ser passível de manipulações de acordo com motivações profissionais ou políticas. Há também a possibilidade de utilização de dados brutos (primários) que evitariam mediações tendenciosas e seriam fáceis de serem reorganizados de acordo com as demandas por informação de cada cidadão, contudo, não é isenta de problemas e uma de suas fraquezas é o viés de regulação, em que apenas parte das informações torna-se visível, reduzindo a capacidade dos usuários de fazerem inferências a partir desse conjunto de dados (MICHENER; BERSCH, 2011).

Para que essa política de transparência seja implementada com efetividade, é imprescindível que haja a pronta disposição de abertura e de remover obstáculos ao acesso à informação, por parte de quem detém poder, bem como prestar informações suficientes ao pleno desvelamento do poder diante daqueles sobre quem ele exerce (GOMES FILHO, 2005).

Espera-se, então, que órgãos e demais entidades públicas apresentem a alocação de recursos, e demais informações pertinentes, de forma compatível com o que a sociedade demanda (MACIEL, et al., 2019), até mesmo porque, como posto por Gomes Filho (2005), transparência no âmbito do Estado, é um imperativo ético-jurídico visto que este pertence à coisa pública e, portanto, deve se comunicar com a sociedade.

\subsection{Lei de Acesso à Informação}

A Lei 12.527, de 18 de novembro de 2011, conhecida como Lei de Acesso à Informação - LAl, foi implementada pela administração pública federal e regulamentada por meio do Decreto no 7.724 , de 16 de maio de 2012, como um instrumento para que as necessidades de informação dos cidadãos sejam tornadas acessíveis e facilitadas, propiciando mecanismos que permitem a pessoas físicas ou jurídicas, independentemente de motivação, receberem informações de seu interesse pelos órgãos públicos (MACIEL, et al., 2019).

As regras que estão previstas na LAI devem ser implementadas por toda a administração pública, por se tratar de lei de caráter nacional, dessa forma, submetem-se a ela os órgãos públicos integrantes da administração direta dos Poderes Executivo, Legislativo, incluindo as Cortes de Contas, e Judiciário e do Ministério Público, as autarquias, as fundações públicas, as empresas públicas, as sociedades de economia mista e demais entidades controladas direta ou indiretamente pela União, estados, Distrito Federal e municípios, bem como, no que couber, as entidades privadas sem fins lucrativos que recebam recursos públicos diretamente do orçamento ou mediante subvenções sociais, contrato de gestão, termo de parceria, convênios, acordo, ajustes ou outros instrumentos congêneres (BRASIL, 2011).

Seu objetivo, de acordo com o disposto no art. $3^{\circ}$, é o de assegurar o direito fundamental de acesso à informação, conforme princípios básicos da administração pública, mediante as seguintes diretrizes: publicidade como regra geral e sigilo como exceção, divulgação de informações de interesse público independentemente de solicitações, utilização de meios de comunicação viabilizados pela tecnologia da informação, fomento à cultura da transparência e o desenvolvimento do controle social da administração pública (BRASIL, 2011).

De acordo com Bitencourt e Reck (2016), são identificadas na LAI características da transparência, tais como a promoção da informação completa, objetiva, confiável e de qualidade, o acesso, a compreensão e os canais totalmente abertos de comunicação, ou seja, engloba os atributos de acesso, abrangência, relevância, qualidade e confiabilidade. 
Para alcançar o objetivo da LAl, a administração pública deve gerir a documentação governamental de forma a franquear sua consulta a todos os que dela necessitem, podendo utilizar sítios virtuais oficiais, na rede mundial de computadores, como ferramenta de divulgação e pesquisa (SILVA NETO et al., 2019).

Segundo Silva, Gomes e Cavalcante (2013), as diretrizes de acesso à informação da LAl subdividem-se em dois eixos, a transparência ativa e a transparência passiva.

O princípio da "transparência ativa" é o ato de promover informações independentemente de requerimentos, ou seja, a lei, em seu artigo $8^{\circ}$, exige que órgãos e entidades públicas publiquem, por iniciativa própria, determinadas informações de interesse público, são elas: registro das competências e estrutura organizacional, endereços e telefones das respectivas unidades e horários de atendimento ao público; registros de quaisquer repasses ou transferências de recursos financeiros; registros das despesas; informações concernentes a procedimentos licitatórios, inclusive os respectivos editais e resultados, bem como a todos os contratos celebrados; dados gerais para o acompanhamento de programas, ações, projetos e obras de órgãos e entidades e; respostas a perguntas mais frequentes da sociedade (BRASIL, 2011).

Por sua vez, a transparência passiva se refere à disponibilização de meios físicos (Serviços de Informação ao Cidadão - SIC) e eletrônicos (e-SIC) para que qualquer pessoa possa buscar outras informações pertinentes às atividades da instituição, mas que não estejam disponíveis na internet. O artigo 10 da LAI informa que qualquer interessado poderá apresentar pedido de acesso a informações a órgãos públicos e restringe exigências excessivas, que possam inviabilizar a solicitação, para a identificação dos requerentes; também obriga à gestão pública a viabilizar solicitações por meio do sítio virtual; bem como veda quaisquer exigências relativas aos motivos determinantes da solicitação de informações de interesse público (BRASIL, 2011).

É importante observar que a LAI propiciou a exceção do sigilo em informações, de forma distinta de outras leis que existiam até então, como por exemplo a Lei de Arquivos N 8.159/1991, que dedicou todo o seu capítulo $\mathrm{V}$ ao acesso e sigilo de documentos públicos, revogado após a aprovação da LAl, assim como a Lei No 11.111/2005 que trazia ainda mais restrições à informações públicas (JARDIM, 2012). Nesse sentido, a LAI pressupõe uma lógica político-jurídica de acesso à informação inserindo o cidadão e suas necessidades no epicentro da mesma (JARDIM, 2012).

Nesse sentido, Barros e Medleg (2018) ressaltam que a LAl tem potencial para promover uma mudança na cultura existente na administração pública, fazendo com que os agentes públicos se conscientizem de que não são eles os detentores das informações, mas, sim, o cidadão.

A Lei 12.527/2011 promove, então, ganhos de qualidade na prestação do serviço público por ter o dever de informar, de forma entendível, sobre o uso de recursos públicos e prestar contas de seus atos, o que possibilita um avanço no que se refere à participação cívica, que passa a poder acompanhar e fiscalizar o poder público (CARVALHO; FREITAS; BARBOSA, 2019).

Esse controle da sociedade perante o poder público, que a LAI proporciona, é visto por Secchin (2008) como um elemento imprescindível ao estímulo de práticas corretas pelos atores sociais, sendo um inibidor de desvios e abusos no trato da coisa pública. Nesse sentido, cabe ao Estado incentivá-lo, criando ferramentas que permitam o exercício da prática da cidadania e participação nas decisões, assim como no controle social do desenvolvimento das políticas públicas (SECCHIN, 2008).

\section{METODOLOGIA}

Do ponto de vista da natureza, a pesquisa é encarada como aplicada pois busca, essencialmente, gerar conhecimentos para a aplicação prática e resolução de problemas específicos identificados no âmbito da sociedade em que vivemos, com vistas a fazer algo de maneira mais eficiente ou eficaz (GIL, 2008), no presente caso, verificar possíveis inconformidades da aplicação da LAl e propor sugestões a fim de modificar tal realidade.

Quanto à abordagem desta pesquisa, teve formato misto, por empregar características da pesquisa quantitativa, na quantificação e tratamento dos dados obtidos nos sítios virtuais das prefeituras de capitais do nordeste, e qualitativa ao se permitir analisar e interpretar dados descritivos e interativos, procurando compreender o problema em questão (CRESWELL, 2007; RICHARDSON, 2012). 
Quanto aos objetivos, possui desígnio exploratório, uma vez que se está a avaliar um fenômeno desconhecido (MARCONI; LAKATOS, 2009), que seria o cumprimento da Lei de Acesso à Informação por parte das prefeituras municipais das capitais nordestinas, tendo, como propósito, buscar mais informações sobre o tema e se familiarizar com o problema, com vistas a delimitá-lo ou a construir hipóteses (GIL, 2008), bem como apresenta características de pesquisa descritiva, considerando que se propôs a expor características de um determinado fenômeno (GIL, 2008).

No tocante a procedimentos técnicos de investigação, Vergara (2016) costuma classificar da seguinte forma: pesquisa de campo, pesquisa de laboratório, documental, bibliográfica, experimental, ex post facto, participante, pesquisa-ação e estudo de caso. Diante desta perspectiva, o estudo é considerado como documental e bibliográfico, sendo operacionalizado por meio da literatura especializada, da leitura e análise das legislações específicas e da consulta e coletas de informações disponíveis nos sítios virtuais do Poder Executivo das capitais nordestinas, que foram o objeto de estudo.

\subsection{Fonte e coleta de dados}

Os sítios virtuais oficiais/principais e de transparência das prefeituras de capitais nordestinas foram as fontes diretas dos dados, onde se encontraram os elementos-chave para diagnosticar se a Lei de Acesso à Informação estava sendo aplicada corretamente. Os sítios oficiais foram localizados por meio de pesquisa na plataforma de busca Google, e os sítios de transparência encontrados em busca nos sítios oficiais.

Como instrumento de coleta de dados, foi criado um formulário estruturado para observação dos sítios virtuais em que foram elencados grupos de requisitos e itens de análise, os quais correspondem às condições estabelecidas pela Lei 12.527/2011, de modo a identificar se cada item estava sendo cumprido integralmente, cumprido parcialmente ou não cumprido pelos sítios virtuais. O período de coleta de dados ocorreu entre 17 de setembro de 2019 e 27 de setembro de 2020. O quadro 1 mostra a relação entre os itens elencados e os respectivos requisitos estabelecidos pela lei, que foram a base do formulário de observação.

Quadro 1 - Itens de observação e requisitos da LAI

\begin{tabular}{|c|c|c|c|}
\hline $\begin{array}{l}\text { Grupos } \\
\text { de } \\
\text { requisitos }\end{array}$ & Itens & Requisitos & $\begin{array}{l}\text { Base legal } \\
\quad(\text { Lei no } \\
12.527 / 2011)\end{array}$ \\
\hline \multirow{10}{*}{ 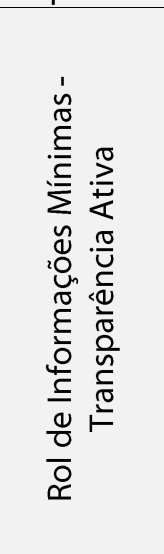 } & 01 & Expor sua estrutura organizacional. & art. $8^{\circ}, \S 1^{\circ}, 1$ \\
\hline & 02 & Exibir suas competências. & art. $8^{\circ}, \S 1^{\circ}, 1$ \\
\hline & 03 & Disponibilizar endereços das unidades organizacionais. & art. $8^{\circ}, \S 10,1$ \\
\hline & 04 & Disponibilizar telefones das unidades organizacionais. & art. $8^{\circ}, \S 10,1$ \\
\hline & 05 & Informar horários de atendimento ao público. & art. $8^{\circ}, \S 1^{\circ}, \mathrm{I}$ \\
\hline & 06 & Informar os repasses ou transferências de recursos financeiros. & art. $8^{\circ}, \S 1^{\circ}, \mathrm{II}$ \\
\hline & 07 & Informar suas despesas. & art. $8^{\circ}, \S 1^{\circ}, \mathrm{III}$ \\
\hline & 08 & $\begin{array}{l}\text { Informar seus procedimentos licitatórios, inclusive os respectivos } \\
\text { editais e resultados, bem como a todos os contratos celebrados. }\end{array}$ & art. $8^{\circ}, \S 1^{\circ}, \mathrm{IV}$ \\
\hline & 09 & $\begin{array}{l}\text { Disponibilizar dados gerais para o acompanhamento de } \\
\text { programas, ações, projetos e obras de órgãos e entidades. }\end{array}$ & art. $8^{\circ}, \S 1^{\circ}, \mathrm{V}$ \\
\hline & 10 & Divulgar respostas às perguntas mais frequentes da sociedade. & art. $8^{\circ}, \S 1 \circ, \mathrm{VI}$ \\
\hline \multirow{5}{*}{ 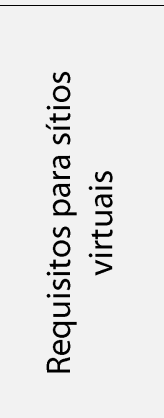 } & 11 & Conter ferramenta de pesquisa de conteúdo no sítio virtual. & art. $8^{\circ}, \S 3^{\circ}, 1$ \\
\hline & 12 & $\begin{array}{l}\text { Possibilitar a gravação de relatórios em diversos formatos } \\
\text { eletrônicos, inclusive abertos e não proprietários, tais como } \\
\text { planilhas e texto. }\end{array}$ & art. $8^{\circ}, \S 3^{\circ}$, II \\
\hline & 13 & $\begin{array}{l}\text { Possibilitar o acesso automatizado por sistemas externos em } \\
\text { formatos abertos, estruturados e legíveis por máquina. }\end{array}$ & art. $8^{\circ}, \S 3^{\circ}$, III \\
\hline & 14 & $\begin{array}{l}\text { Divulgar em detalhes os formatos utilizados para estruturação da } \\
\text { informação, no sítio virtual. }\end{array}$ & art. $8^{\circ}, \S 3^{\circ}, \mathrm{IV}$ \\
\hline & 15 & Garantir a autenticidade e a integridade das informações. & art. $8^{\circ}, \S 3^{\circ}, \mathrm{V}$ \\
\hline
\end{tabular}




\begin{tabular}{|c|c|c|c|}
\hline & 16 & Manter atualizadas as informações disponíveis para acesso. & art. $8^{\circ}, \S 3^{\circ}, \mathrm{Vl}$ \\
\hline & 17 & $\begin{array}{l}\text { Indicar local e instruções que permitam ao interessado comunicar- } \\
\text { se, por via eletrônica ou telefônica, com o órgão ou entidade } \\
\text { detentora do sítio. }\end{array}$ & art. $8^{\circ}, \S 3^{\circ}, \mathrm{VII}$ \\
\hline & 18 & Ter acessibilidade às pessoas com deficiência. & $\begin{array}{l}\text { art. } 8^{\circ}, \S 3 \circ, \\
\text { VIII }\end{array}$ \\
\hline \multirow{7}{*}{ 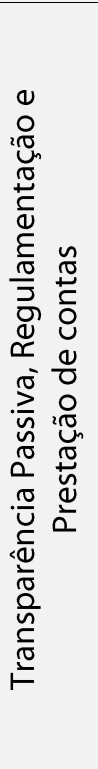 } & 19 & $\begin{array}{l}\text { Disponibilizar, nos órgãos e entidades da Prefeitura, local } \\
\text { específico para prestar Serviços de Informações ao Cidadão com } \\
\text { procedimentos formais e gratuitos para a obtenção de } \\
\text { informações. }\end{array}$ & art. $9^{\circ}, \mathrm{I}$ \\
\hline & 20 & $\begin{array}{l}\text { Disponibilizar, no sítio virtual oficial da Prefeitura, área para } \\
\text { encaminhamento de pedidos de acesso a informações. }\end{array}$ & art. $10, \S 2^{\circ}$ \\
\hline & 21 & $\begin{array}{l}\text { Realizar audiências públicas, consultas públicas ou incentivo à } \\
\text { participação popular em que informações da instituição sejam } \\
\text { divulgadas. }\end{array}$ & art. $9^{\circ}, \mathrm{II}$ \\
\hline & 22 & Regulamentação da LAI por legislação própria. & art. 45 \\
\hline & 23 & $\begin{array}{l}\text { Divulgar, no sítio virtual oficial, relatório estatístico anual } \\
\text { contendo a quantidade de pedidos de informação recebidos, } \\
\text { atendidos e indeferidos, bem como informações genéricas sobre } \\
\text { os solicitantes. }\end{array}$ & art. 30, III \\
\hline & 24 & $\begin{array}{l}\text { Divulgar, no sítio virtual oficial, o rol de documentos classificados } \\
\text { em cada grau de sigilo. }\end{array}$ & art. 30,11 \\
\hline & 25 & $\begin{array}{l}\text { Divulgar, no sítio virtual oficial, as informações que tenham sido } \\
\text { desclassificadas nos últimos } 12 \text { meses. }\end{array}$ & art. 30, I \\
\hline
\end{tabular}

Fonte: Adaptado de Brasil (2011).

\subsection{Análise dos Dados}

Por ser uma pesquisa de método quanti-qualitativo, os dados obtidos pela observação dos sítios virtuais foram tabulados no programa Microsoft Office Excel 2013 e apreciados pelo método da análise documental. Para Richardson (2012), a análise documental consiste em uma série de operações que visam estudar e analisar um ou vários documentos para descobrir as circunstâncias sociais e econômicas com as quais podem estar relacionadas. Para tal fim, o método escolhido foi o histórico, que consiste em estudar os documentos visando investigar os fatos sociais e suas relações com o tempo sócio-cultural-cronológico (RICHARDSON, 2012).

\section{RESULTADOS E DISCUSSÕES}

Os resultados da pesquisa estão apresentados mediante três agrupamentos de requisitos da Lei de Acesso à Informação, são eles: Rol de informações mínimas - Transparência Ativa; Requisitos para sítios virtuais; Transparência passiva, regulamentação e prestação de contas. Nas tabelas a seguir, os itens correspondem aos requisitos identificados no Quadro 1, bem como são apresentados quantos dos nove municípios pesquisados cumprem integralmente, parcialmente ou não cumprem cada item.

$\mathrm{O}$ art. $8^{\circ}$ da LAl, em seu $\S 1^{\circ}$, elenca algumas informações mínimas que devem ser apresentadas à população independente de solicitação, demonstrando transparência ativa por parte da administração pública. A tabela 1 apresenta os resultados. 
Tabela 1 - Rol de Informações Mínimas - Transparência Ativa

\begin{tabular}{cccc}
\hline Itens & Cumprem & $\begin{array}{c}\text { Cumprem } \\
\text { parcialmente }\end{array}$ & Não cumprem \\
\hline 01 & 08 & 01 & \\
02 & 08 & 01 & \\
03 & 09 & & \\
04 & 09 & & 02 \\
05 & 07 & 01 & \\
06 & 08 & & \\
07 & 09 & 03 & 04 \\
08 & 06 & 05 & 02 \\
09 & & 07 & \\
10 & & & \\
\hline
\end{tabular}

Fonte: Dados da pesquisa (2020).

O item 01 expunha a exigência de exibir a estrutura organizacional dos órgãos, quesito cumprido integralmente por 08 prefeituras e parcialmente pela Prefeitura de São Luís, a qual não apresentava a estrutura de forma completa. A mesma situação se deu no item 02 , que verificou a exposição de competências. Observou-se que, apesar de a maioria das prefeituras cumprirem estes itens em seus sítios virtuais, por vezes não estavam em locais facilmente visíveis e, em algumas vezes, expunham apenas as leis de criação das secretarias, órgãos e entidades, que possuem linguagem não acessível a parte da população.

O item 03 abordou a disponibilização de endereços e o item 04 a divulgação de telefones das unidades organizacionais, o que vem sendo cumprido por todas as prefeituras. Algumas delas possuem o diferencial de oferecer a localização de suas unidades organizacionais por mapa, através de uma extensão do mapa da empresa Google, o que promove melhor acesso do cidadão ao órgão de seu interesse. Já o item 05, que se trata da disponibilização do horário de funcionamento das unidades organizacionais, apesar de ser um requisito simples de ser implementado, foi cumprido por 07 prefeituras, mas descumpridos pela prefeitura de Natal e São Luís.

Os itens 06 e 07 se referem à divulgação das receitas e despesas, que também são requisitos encontrados no Art. 48-A, I e II, da Lei Complementar 101/2000 (Lei de Responsabilidade Fiscal) e na Lei da Transparência. A disponibilização das receitas foi cumprida integralmente por 08 sítios e parcialmente pela Prefeitura de Natal, a qual, no período da pesquisa, apenas informava as receitas relacionadas às ações de combate ao Covid-19. O item 07, referente às despesas, foi cumprido pelos 09 municípios pesquisados. Nesses quesitos, destacaram-se as Prefeituras de João Pessoa e Teresina que expunham breves explicações sobre despesas e receitas, o que possibilita melhor entendimento destas informações.

Informações que concernem a procedimentos licitatórios também são exigências da LAl, observadas no item 08 , em que se cobra a exposição de todos os processos, inclusive os respectivos editais e resultados, bem como todos os contratos celebrados. O cumprimento deste item foi verificado integralmente nos sítios de 06 prefeituras, e de forma parcial em Natal, São Luís e Teresina. Em Natal, existia o campo para contratos, mas não estavam sendo exibidos, enquanto em São Luís havia um redirecionamento para o site do Tribunal de Contas Estadual, que não apresentava todos os contratos de forma clara. O problema identificado em Teresina foi a existência de campos distintos para exibição das informações sobre licitações. Em seu sítio de transparência havia uma opção que gerava relatório com informações básicas das licitações, enquanto no sitio principal havia um campo denominado "licitações" em que os documentos estavam dispostos de forma aleatória, o que dificulta a verificação da existência de documentos de todos os certames.

Quanto ao item 09, trata da disponibilização de dados gerais para acompanhamento de programas, ações, projetos e obras, requisito cumprido parcialmente em 05 capitais e não cumprido em Aracaju, Natal, Salvador e São Luís. As prefeituras que cumpriram parcialmente o requisito geralmente divulgam as obras que estão em andamento na cidade, com destaque para Fortaleza que exibe um mapa das obras com informações sobre elas. Não foram encontradas informações sobre projetos, programas e ações, de forma a possibilitar o acompanhamento de metas e indicadores em nenhum dos sítios virtuais. 
Apresentar respostas às perguntas mais frequentes da sociedade é o requisito do item 10, que foi cumprido parcialmente por 08 prefeituras e não cumprido apenas por Teresina. Compreendeu-se que o atendimento foi parcial pois, em geral, as perguntas inseridas eram voltadas para a usabilidade dos sítios virtuais e sobre transparência, o que geralmente divergia do apresentado nos relatórios estatísticos de acesso à informação, que apontavam maior quantidade de questionamentos para outras áreas, principalmente relacionadas a serviços ao cidadão.

Para que os mecanismos de transparência ativa sejam facilitados à população, a LAl definiu que tais informações sejam prestadas por meio de sítios virtuais, e, no que tange a promover maior funcionalidade aos mesmos, definiu alguns requisitos em seu art. $8^{\circ}, \S 3^{\circ}$. Os resultados do cumprimento destes requisitos, por parte das prefeituras nordestinas, se encontram na tabela 2.

Tabela 2 - Requisitos para sítios virtuais

\begin{tabular}{cccc}
\hline Itens & Cumpre & $\begin{array}{c}\text { Cumpre } \\
\text { parcialmente }\end{array}$ & Não cumpre \\
\hline 11 & 03 & 05 & 01 \\
12 & & 08 & 01 \\
13 & & 09 & 07 \\
14 & 03 & 02 & \\
15 & 07 & 06 & \\
16 & 08 & 02 & 02 \\
17 & & 01 & \\
18 & Fonte: Dados da pesquisa (2020).
\end{tabular}

A primeira exigência referente aos sítios virtuais éa presença de ferramenta de pesquisa de conteúdo, elencada no item 11. Para o cumprimento do item, foi considerado que essa ferramenta deveria existir tanto no sítio virtual oficial quanto no relacionado à transparência municipal, o que foi cumprido pelos municípios de Natal, Recife e São Luís, por outro lado, o município de Teresina não possibilitava tal ferramenta. Os demais municípios permitiam pesquisa em apenas um dos canais, compreendendo-se atendimento parcial. Cumpre destacar que, apesar de existir o campo de pesquisa, em alguns sítios virtuais as ferramentas abrangiam apenas parte do conteúdo, o que desvirtua da finalidade imposta em lei.

Outro requisito, elencado como item 12, é a possibilidade de gravação de relatórios em diversos formatos eletrônicos, inclusive abertos e não proprietários. Dos diversos relatórios disponibilizados pelas prefeituras em seus sítios oficiais e de transparência, geralmente os relacionados às receitas e despesas são os disponibilizados em formatos abertos e não proprietários, os demais são costumeiramente apresentados em PDF (Portable Document Format), o que dificulta a leitura por máquina e afeta a acessibilidade aos documentos. Diante disso, compreende-se que 08 prefeituras tiveram o cumprimento parcial do item, o qual não foi cumprido pelo município de Salvador por não terem sido encontrados relatórios em formato não proprietário dentre os apresentados em seus sítios virtuais.

No mesmo sentido, o item 13 buscou verificar o cumprimento da possibilidade de acesso automatizado por sistemas externos em formatos abertos, estruturados e legíveis por máquina, ou seja, referese ao tipo de acesso em que não haja obstáculos à leitura de arquivos, por seu formato, senhas ou captchas. Esse quesito foi cumprido parcialmente pelas 09 prefeituras devido ao uso predominante de informações em PDF que, de acordo com Pires (2015), não é um formato aberto, estruturado e legível por máquina. Além disso, em Teresina foi observada a necessidade de decifrar captchas (ferramenta para impedir a ação de softwares automatizados, conhecidos como bots) para acessar algumas informações, como as Receitas, despesas e acompanhamento de obras, o que prejudica a acessibilidade por não possibilitar a leitura de tela e, mesmo quando oferecem versões em áudio, não contempla os usuários com deficiência visual e auditiva (BRASIL, 2014).

Quanto a divulgação em detalhes dos formatos utilizados para estruturação da informação, item 14, foi observado cumprimento parcial nos municípios de João Pessoa e Recife, os quais disponibilizam campo específico com alguns conjuntos de dados abertos estruturados e com explicações sobre seus formatos 
utilizados, contudo, não abrange todas as informações disponíveis em seus sítios virtuais. Os demais municípios pesquisados não cumpriram o requisito da lei. A esse respeito, o W3C (2011) afirma que alguns sistemas dedicados têm seus próprios formatos de dados para guardar ou exportar dados, sendo importante indicar contatos dos fornecedores para maiores informações, além disso, é recomendado disponibilizar dados em formatos não proprietários para que o acesso a informações públicas não seja restrito aos interesses de companhias e organizações.

A LAI também preconiza a garantia de itens relacionados à segurança da informação, tais como a autenticidade e integridade, no inciso IV do art. $8^{\circ}, \S 3^{\circ}$. Para verificar esse requisito, item 15 , compreendeu-se como autênticas as informações que estavam publicadas em sítios virtuais com o domínio "município.gov.br" ou "município.sigladoestado.gov.br" e, como íntegros, os sítios virtuais que utilizam criptografia na conexão (HTTPS) entre o servidor e o dispositivo utilizado pelo cidadão (ARAÚJO; MARQUES, 2019). Cumpriram totalmente esses requisitos as prefeituras de Fortaleza, João Pessoa e Natal, enquanto as demais cumpriram parcialmente por não ter sido verificado o requisito de integridade em seus sítios virtuais.

A atualização de informações também foi verificada, no item 16, tendo sido observado o cumprimento parcial desse requisito apenas nos municípios de Salvador e Teresina, que dispunham de algumas informações que não estavam atualizadas no ano de 2020. Os demais municípios cumpriram eficientemente este item.

O item 17 buscou identificar se o sítio virtual indica local e instruções que permitam aos indivíduos interessados comunicar-se, por via eletrônica ou telefônica, com o órgão ou entidade detentora do sítio. $\mathrm{O}$ requisito foi cumprido por 08 prefeituras, apenas a de Teresina teve cumprimento parcial pois seu sítio de transparência havia apenas um campo denominado "fale conosco", o qual não funcionou nas tentativas de acesso.

Atender às pessoas com deficiência por meio do sítio virtual ou mesmo no Serviço de Informação ao Cidadão presencial também é um requisito estabelecido na LAl, elencada como item 18. Não havia nenhuma ferramenta de acessibilidade nos sítios virtuais de Salvador e Teresina, nos demais, o cumprimento foi compreendido como parcial pois as ferramentas estavam dispostas em apenas um dos sítios virtuais, ou então possibilitavam ferramentas apenas para um tipo de deficiência, em geral visuais ou auditivas, não abrangendo todas as necessidades de acessibilidade.

A esse respeito, é importante frisar que a adequação dos sítios e portais deve se basear no Modelo de Acessibilidade em Governo Eletrônico (e-MAG), que foi elaborado nos termos do art. 17 da Lei n 10.098, de 19 de dezembro de 2000, e do art. $9^{\circ}$ da Convenção sobre os Direitos das Pessoas com Deficiência, aprovada pelo Decreto Legislativo n 186, de 9 de julho de 2008, bem como para também atender à Lei Brasileira de Inclusão, Lei no 13.146, de 6 de julho de 2015.

Para facilitar a avaliação da acessibilidade dos sítios virtuais, o Governo Federal possui um Avaliador e Simulador de Acessibilidade em Sítios (ASES) ${ }^{1}$, que avalia diversos critérios da estrutura dos sítios eletrônicos. Por meio desta ferramenta, foi realizada avaliação dos sítios oficiais e sítios de transparência das prefeituras nordestinas, conforme exposto na Tabela 3.

Tabela 3 - Percentuais de avaliação de acessibilidade

\begin{tabular}{ccc}
\hline Município & Sítio Oficial & Sítio de Transparência \\
\hline Aracaju & $90,06 \%$ & $77,87 \%$ \\
Fortaleza & $77,51 \%$ & $67,74 \%$ \\
João Pessoa & $86,75 \%$ & $68,54 \%$ \\
Maceió & $78,59 \%$ & $74,03 \%$ \\
Natal & $75,54 \%$ & $73,07 \%$ \\
Recife & $73,34 \%$ & $73,58 \%$ \\
Salvador & $79,43 \%$ & $68,92 \%$ \\
São Luís & $76,66 \%$ & $91,83 \%$ \\
Teresina & $74,61 \%$ & $72,89 \%$ \\
\hline
\end{tabular}

Fonte: Adaptado de Brasil (2020).

\footnotetext{
${ }^{1}$ Presente no endereço eletrônico https://asesweb.governoeletronico.gov.br.
} 
O ASES indica, na tela de avaliação, que o ideal é ter o cumprimento dos requisitos acima de $95 \%$, o que não foi obtido por nenhum dos sítios virtuais pesquisados, assim como alerta para o resultado abaixo de $70 \%$, o que ocorreu com os sítios virtuais de transparência de Fortaleza, João Pessoa e Salvador. É importante destacar que esses percentuais se referem a uma avaliação realizada no dia 27 de setembro de 2020, podendo variar de acordo com alterações e novas informações inseridas nos sítios virtuais.

Do mesmo modo que a LAl versa sobre a necessidade de prestar informações de forma proativa, também obriga ao poder público, e entidades que recebem recursos deste, a aceitarem as solicitações de informações advindas da população, o que é denominado como transparência passiva. Ainda orienta a elaboração de regulamentação própria e uma pequena prestação de contas, informando-se as estatísticas decorrentes das atividades impostas pela lei. Os resultados dos últimos itens pesquisados se encontram na Tabela 4.

\begin{tabular}{cccc}
\multicolumn{4}{c}{ Tabela 4 - Transparência Passiva, Regulamentação e Prestação de contas } \\
\hline Itens & Cumpre & $\begin{array}{c}\text { Cumpre } \\
\text { parcialmente }\end{array}$ & Não cumpre \\
\hline 19 & 08 & & 01 \\
20 & 09 & & \\
21 & 09 & & \\
22 & 09 & 03 & 01 \\
23 & 05 & & 09 \\
24 & & & 09 \\
25 & & & \\
\hline
\end{tabular}

Fonte: Dados da pesquisa (2020).

O item 19 aferiu a determinação sobre existência de local específico para prestar Serviços de Informações ao Cidadão (SIC), com procedimentos formais e gratuitos para a obtenção de informações. Foi apurado que apenas o município de São Luís não apresentava este serviço. Apesar de o Decreto Municipal nº 47.272/2015, em seu art. 12, determinar a presença de unidades físicas para o SIC, não há menção a estes nos sítios virtuais, o que reflete no relatório estatístico do ano de 2019 , o qual informa que todas as solicitações de informações foram realizadas pela internet.

Aos que preferirem não se deslocar para um órgão público, a LAl também oferece o direito de requisitar informações por meio da internet. Nesse sentido, o item 20 observa a existência de área para encaminhamento de pedidos de acesso a informações nos sítios virtuais, que foi cumprido por todas as cidades pesquisadas.

Outro aspecto contemplado pela LAI é a participação social, elencada no item 21.0 art. 90, II, determina que haja formas de divulgação por meio de audiências públicas, consultas públicas ou incentivo à participação popular. A pesquisa certificou que todas as cidades realizam, ao menos, audiências sobre as leis orçamentárias, determinadas pela Lei de Responsabilidade Fiscal, entre várias outras, o que possibilitou o cumprimento do requisito legal por todos os municípios.

Por sua vez, o item 22 tratou da necessidade de regulamentação própria da Lei 12.527/2011 nos estados, Distrito Federal e municípios brasileiros. Esta é mais uma exigência cumprida por todos os municípios pesquisados, sendo que João Pessoa, Recife e Salvador possuem leis próprias de acesso à informação, enquanto as demais cidades optaram por regulamentar a LAI por meio de decreto.

O item 23 abordou a divulgação do relatório estatístico anual contendo a quantidade de pedidos de informação recebidos, atendidos e indeferidos, bem como informações genéricas sobre os solicitantes, como, por exemplo, gênero, faixa etária, grau de instrução, local de residência, entre outros. O cumprimento deste requisito foi integral em 05 municípios (Fortaleza, João Pessoa, Recife, São Luís e Teresina), parcial nos municípios de Aracaju, Maceió e Natal, os quais não informaram dados genéricos dos solicitantes, e não foi cumprido pelo município de Salvador, que teve a última atualização do relatório estatístico no ano de 2018.

Os últimos itens avaliados, 24 e 25, trataram, respectivamente, do requisito de divulgação do rol de documentos classificados e desclassificados em cada grau de sigilo no último ano. Apesar de haver a 
possibilidade de conferir graus de sigilo por decreto municipal, não há menção alguma nos sítios virtuais pesquisados. Como haveria a possibilidade de mencionarem que não existem documentos classificados e/ou desclassificados, entende-se que são requisitos descumpridos por todos os municípios.

Finda-se a apresentação de resultados com o quantitativo e percentual de cumprimento dos itens por parte do Poder Executivo das capitais nordestinas, demonstrados na tabela 5.

Tabela 5 - Percentual de Cumprimento da LAI por cidade

\begin{tabular}{cccc}
\hline Município & Cumpre & $\begin{array}{c}\text { Cumpre } \\
\text { parcialmente }\end{array}$ & Não cumpre \\
\hline João Pessoa & $64 \%$ & $28 \%$ & $8 \%$ \\
Fortaleza & $64 \%$ & $24 \%$ & $12 \%$ \\
Recife & $64 \%$ & $24 \%$ & $12 \%$ \\
Maceió & $56 \%$ & $32 \%$ & $12 \%$ \\
Aracaju & $56 \%$ & $28 \%$ & $16 \%$ \\
Natal & $52 \%$ & $28 \%$ & $20 \%$ \\
Salvador & $52 \%$ & $24 \%$ & $24 \%$ \\
Teresina & $48 \%$ & $28 \%$ & $24 \%$ \\
São Luís & $44 \%$ & $32 \%$ & $24 \%$ \\
\hline
\end{tabular}

Fonte: Dados da pesquisa (2020)

A classificação obtida com o percentual de cumprimento dos itens pode ser comparada, resguardadas as devidas metodologias, ao posicionamento que os municípios obtiveram em outros estudos, como na Escala Brasil Transparente, realizado pela Controladoria Geral da União (BRASIL, 2018) e no Ranking Nacional da Transparência, realizado pelo Ministério Público Federal (BRASIL, 2016), conforme apresentado na Figura 1.

Figura 1 - Variação do ranking das capitais nordestinas

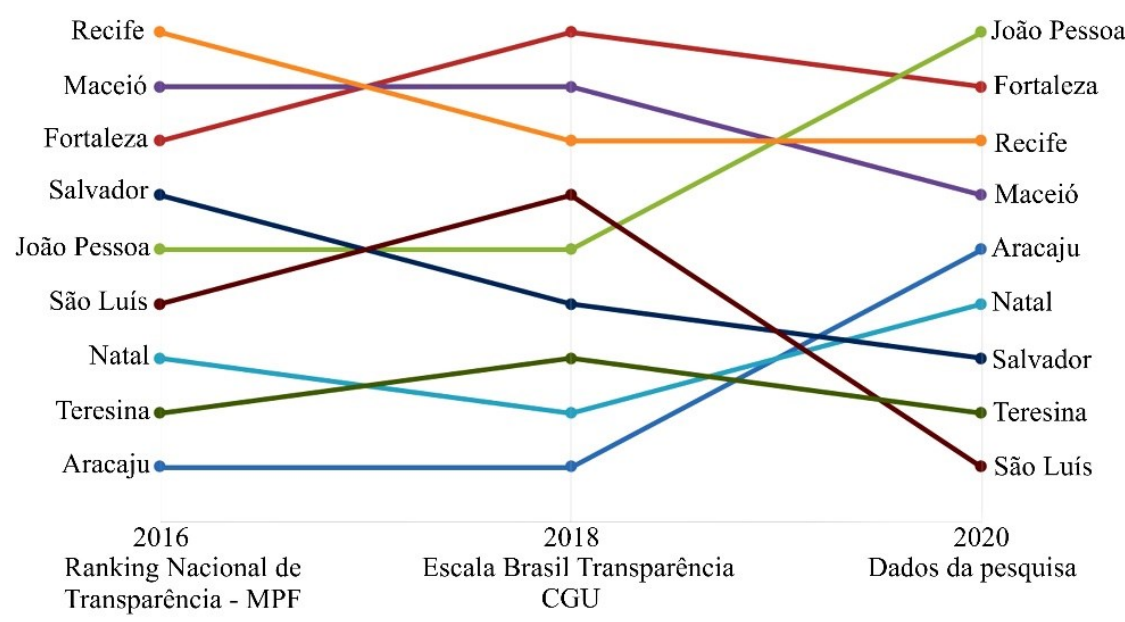

Fonte: Adaptado de Brasil (2016, 2018).

A Figura 1 mostra que, no interstício de tempo compreendido entre as pesquisas, as Prefeituras das cidades de Fortaleza, Recife e Maceió estiveram sempre nas melhores posições entre as capitais nordestinas, 0 que pode indicar o esforço das gestões para a manutenção da transparência. Também é aparente a melhoria de posição dos municípios de João Pessoa e Aracaju, bem como a perda de posições das cidades de Salvador e São Luís.

\section{CONSIDERAÇÕES FINAIS}

Diante do volume de recursos que possuem, a densidade populacional, o destaque que recebem nos noticiários, entre outras características, as capitais dos estados brasileiros podem ser compreendidas como 
referências para as diversas outras cidades. Assim, é de singular importância que o Poder Executivo das capitais nordestinas proporcionem bons resultados no que se refere à aplicação da LAl e à política de transparência efetiva e comprometida com a sociedade.

A respeito do que foi pesquisado, pode-se inferir que o resultado geral dos 25 itens elencados é positivo, com sete capitais cumprindo totalmente mais da metade dos requisitos exigidos em lei para seus sítios virtuais. O percentual de cumprimento parcial variou entre $24 \%$ e $32 \%$ e o de não cumprimento dos requisitos variou entre $8 \%$ e $24 \%$.

No que se refere ao objetivo específico de verificar o cumprimento do grupo de requisitos de transparência ativa, denominado na lei como "rol de informações mínimas", teve resultado proveitoso, com oito itens cumpridos totalmente pela maioria das prefeituras. Os itens que tiveram cumprimento menos efetivo foram os relacionados ao acompanhamento de programas e ações, e a exposição das perguntas mais frequentes da sociedade.

Para melhorar o cumprimento da transparência ativa destes municípios, sugere-se: agrupar as informações contidas entre os itens 01 a 05 no campo destinado a cada secretaria, órgão ou entidade do poder público; adotar o uso de linguagem clara, resumida e compreensível, além de elaborar textos e vídeos explicativos sobre determinados conteúdos, como por exemplo, nos campos destinados às competências, receitas, despesas e licitações, de forma a facilitar a inferability, ou seja, a maior capacidade de inferências do público; organizar o campo das licitações e contratos para que essas informações estejam vinculadas; promover a disponibilização do acompanhamento dos diversos programas, obras e ações de forma atualizada, para que a população passe a ter maior controle social do alcance das metas e indicadores; elencar no campo de perguntas frequentes, as perguntas mais realizadas por secretaria, órgão ou entidade.

Quanto à verificação referente à transparência passiva, regulamentação e prestação de contas, os municípios possuem resultado satisfatório, com cinco dos sete itens sendo cumpridos de forma eficiente pelas prefeituras. Sugere-se a criação de um campo destinado a informar a classificação de informações sigilosas, mesmo que ainda não haja informações, de forma a indicar à população que o Poder Executivo municipal não restringe nenhuma informação além das que estão resguardadas em lei; e que se aprimorem as análises estatísticas de solicitação de informações, possibilitando estudos do tipo de público que costuma realizar este tipo de solicitação, e poder planejar ações de informação voltadas aos mesmos.

O resultado menos satisfatório foi alusivo ao objetivo de identificar se estão sendo cumpridos os requisitos mínimos de configuração para os sítios virtuais, com apenas dois dentre oito requisitos sido cumpridos pela maioria dos municípios. Observou-se que a maioria dos itens não cumpridos de maneira efetiva ocorrem devido a disposição de informações nos sítios virtuais, o que poderia ser solucionado com estratégias diferenciadas na reelaboração dos portais existentes e nas diversas possibilidades de disponibilização de dados, de forma a cumprir a lei a contento.

Para auxiliar na resolução desses óbices, sugere-se: a disponibilização prioritária de informações em arquivos de formatos abertos, não proprietários e legíveis por máquina, com data de atualização e possibilidade de serem encontradas pela ferramenta de pesquisa; viabilizar a estruturação de todos os sítios e alocação de ferramentas nos mesmos de forma a tornar acessíveis as informações a todos os que delas necessitam; assegurar a autenticidade e a integridade dos sítios virtuais para que os cidadãos tenham segurança das informações que estão sendo prestadas.

Indubitavelmente, o poder público somente passará a exceder o estrito cumprimento dos requisitos legais a partir do momento em que a sociedade assim exigir. Portanto, cumpre aos legisladores, órgãos de controle, imprensa, bem como instituições significativas, como as universidades, que estejam aliados à sociedade na permanente cobrança dos gestores públicos, bem como na elaboração de ideias e proposituras para que haja o aprimoramento do acesso à informação, de forma a possibilitar maior controle social e a accountability na gestão pública.

Diante do exposto, propõe-se que outros pesquisadores prossigam na realização de avaliações como a deste artigo no Poder Executivo de outras cidades, bem como dos diversos órgãos e entidades subordinados à lei, de forma a acompanhar se o cumprimento dela evoluirá ao longo dos anos. Outrossim, também se sugere 
estudos que comparem as informações prestadas em gestões distintas, e como é observada a política de acesso à informação nas mudanças de prefeitos, governadores e outras autoridades de órgãos públicos.

\section{REFERÊNCIAS}

ABRUCIO, F. L.; LOUREIRO, M. R. Finanças públicas, democracia e accountability. In: ARVATE, P. R.; BIDERMAN, C. (org.). Economia do setor público no Brasil. Rio de Janeiro: Elsevier, 2004. p. 75-102. Disponível em: https://pesquisa-eaesp.fgv.br/sites/gvpesquisa.fgv.br/files/publicacoes/P00298_1.pdf. Acesso em: 21 nov. 2019.

AMORIM, F. B.; STADLER, A. O acesso à informação na gestão pública: dificuldades enfrentadas pelo poder executivo municipal de Londrina/PR. Revista de Gestão e Secretariado, [S.I.], v. 10, n. 2, p. 246-268, ago. 2019. ISSN 2178-9010. Disponível em: https://www.revistagesec.org.br/secretariado/article/view/873. Acesso em: 21 nov. 2019.

ARAÚJO, L. P. M. DE; MARQUES, R. M. Uma análise da transparência ativa nos sites ministeriais do Poder Executivo Federal brasileiro. Revista Ibero-Americana de Ciência da Informação, v. 12, n. 2, p. 419-439, 3 jan. 2019. Disponível em: https://periodicos.unb.br/index.php/RICl/article/view/9236. Acesso em: 24 set. 2020.

BARROS, D. S.; MEDLEG, G. R. Acesso à informação na região nordeste: balanço da criação da LAI nos estados e o processo de sua regulamentação no Maranhão. Perspect. ciênc. inf., Belo Horizonte, v. 23, n. 1, p. 218, jan. 2018. Disponível em: http://www.scielo.br/scielo.php?script=sci_arttext\&pid=S141399362018000100002\&lng=en\&nrm=iso. Acesso em: 21 nov. 2019.

BITENCOURT, C. M.; RECK, J. R. Controle da transparência na contratação pública no Brasil - o acesso à informação como forma de viabilizar o controle social da Administração Pública. Revista do Direito, Santa Cruz do Sul, v. 2, n. 49, p. 96-115, set. 2016. ISSN 1982-9957. Disponível em: https://online.unisc.br/seer/index.php/direito/article/view/7892. Acesso em: 22 dez. 2019.

BRASIL. [Constituição (1988)]. Constituição da República Federativa do Brasil de 1988. Brasília, DF: Presidência da República, 1988. Disponível em: http://www.planalto.gov.br/ccivil_03/constituicao/constituicao.htm. Acesso em: 21 nov. 2019.

BRASIL. Lei no 12.527 , de 18 de novembro de 2011. Regula o acesso a informações previsto no inciso XXXIII do art. $5^{\circ}$, no inciso Il do $\S 3^{\circ}$ do art. 37 e no $\S 2^{\circ}$ do art. 216 da Constituição Federal; altera a Lei no 8.112 , de 11 de dezembro de 1990; revoga a Lei no 11.111, de 5 de maio de 2005, e dispositivos da Lei no 8.159, de 8 de janeiro de 1991; e dá outras providências. [2011]. Disponível em: http://www.planalto.gov.br/ccivil_03/_ato2011-2014/2011/lei//12527.htm. Acesso em: 21 nov. 2019.

BRASIL. eMAG Modelo de Acessibilidade em Governo Eletrônico. Brasília: MP, SLTI, 2014. Disponível em: http://emag.governoeletronico.gov.br/. Acesso em: 25 set. 2020.

BRASIL. Ministério Público Federal. Ranking Nacional da Transparência. 2016. Disponível em: http://combateacorrupcao.mpf.mp.br/ranking. Acesso em: 10 jan. 2020.

BRASIL. Controladoria Geral da União. Escala Brasil Transparente - Avaliação $360^{\circ}$. 2018. Disponível em: http://transparencia.gov.br/brasiltransparente?ordenarPor=posicao\&direcao=asc. Acesso em: 10 jan. 2020.

BRASIL. Governo Federal. ASES - Avaliador e simulador de acessibilidade em sítios. Governo Federal, 2020. Disponível em: https://asesweb.governoeletronico.gov.br. Acesso em: 27 set. 2020.

CARVALHO, I. C. S de; FREITAS, K. A.; BARBOSA, C. R. Tecnologia da informação como apoio à participação social. Pretexto, v. 20, n. 3, p. 55-67, jul./set. 2019. Disponível em: http://www.fumec.br/revistas/pretexto/article/view/6027. Acesso em: 22 nov. 2019. 
CRESWELL, J. W. Projeto de pesquisa: métodos qualitativo, quantitativo e misto. 2. ed. Porto Alegre: Artmed, 2007.

CRUZ, C. F; SILVA, L. M.; SANTOS, R. Transparência da gestão fiscal: um estudo a partir dos portais eletrônicos dos maiores municípios do Estado do Rio de Janeiro. Contabilidade, Gestão e Governança, v. 17, n. 3, p. 102-115, set./dez 2009. Disponível em: https://www.revistacgg.org/contabil/article/view/86/pdf_121. Acesso em: 19 dez. 2019.

DREHMER, A.; RAUPP, F. M. Comparando Transparência Passiva na esfera estadual: Executivo, Legislativo e Judiciário. Sociedade, Contabilidade e Gestão, v. 13, n. 2, p. 28-46. 28 ago. 2018. Disponível em: https://revistas.ufrj.br/index.php/scg/article/view/13673. Acesso em: 21 nov. 2019.

GIL, A. C. Como elaborar projetos de pesquisa. 6. ed. São Paulo: Atlas, 2008.

GOMES FILHO, A. B. O desafio de implementar uma gestão pública transparente. In: CONGRESO INTERNACIONAL DEL CLAD SOBRE LA REFORMA DEL ESTADO Y DE LA ADMINISTRACIÓN PÚBLICA, X, 2005, Santiago, Chile. Anais eletrônicos [...] Santiago: CLAD, 2005. Disponível em: siare.clad.org/fulltext/0052549.pdf. Acesso em: 21 dez. 2019.

JARDIM, J. M. A lei de acesso à informação pública: dimensões político-informacionais. Tendências da Pesquisa Brasileira em Ciência da Informação, v. 5, n. 1, 2012. Disponível em: http://hdl.handle.net/20.500.11959/brapci/119450. Acesso em: 21 nov. 2019.

MACIEL, R. G. et al. Sistema Eletrônico do Serviço de Informação ao Cidadão (e-SIC) e sua contribuição para a transparência: uma experiência gerencial em uma universidade federal. Perspect. ciênc. inf., Belo Horizonte, v. 24, n. 2, p. 143-164, jun. 2019. Disponível em:

http://www.scielo.br/scielo.php?script=sci_arttext\&pid=S1413-99362019000200143\&lng=en\&nrm=iso.

Acesso em: 21 nov. 2019.

MARCONI, M. de A.; LAKATOS, E. M. Metodologia do trabalho científico: procedimentos básicos, pesquisa bibliográfica, projeto e relatório, publicações e trabalhos científicos. 7. ed. São Paulo: Atlas, 2009.

MICHENER, G.; BERSCH, K. Conceptualizing the quality of transparency. Political Concepts, v. 49, p. 1-27, 2011. Disponível em: http://www.concepts-methods.org/Files/WorkingPaper/PC_49_Michener_Bersch.pdf. Acesso em: 21 dez. 2019.

ONU. Declaração Universal dos Direitos Humanos. 1948. Disponível em: https://nacoesunidas.org/direitoshumanos/declaracao/. Acesso em: 22 dez. 2019.

PAES, E. B. A construção da Lei de Acesso à Informação Pública no Brasil: desafios na implementação de seus princípios. Revista do Serviço Público, v. 62, n. 4, p. 407-423, 28 jan. 2011. Disponível em: https://revista.enap.gov.br/index.php/RSP/article/view/80. Acesso em: 22 nov. 2019.

PIRES, M. T. Guia de Dados Abertos. São Paulo: Governo do Estado de São Paulo, 2015. Disponível em: https://ceweb.br/guias/dados-abertos/. Acesso em: 23 set. 2020.

RAUPP, F. M. Construindo a accountability em câmaras municipais do estado de Santa Catarina: uma investigação nos portais eletrônicos. 2011. Tese (doutorado em Administração) - Curso de Administração, Universidade Federal da Bahia, Salvador, 2011. Disponível em: http://www.adm.ufba.br/pt-

$\mathrm{br} /$ publicacao/construindo-accountability-camaras-municipais-estado-santa-catarina-investigacao-portais. Acesso em: 21 dez. 2019.

RICHARDSON, R. J. Pesquisa Social: métodos e técnicas. 3. ed. revista e ampliada. São Paulo: Atlas, 2012.

ROCHA, A. C. Accountability na Administração Pública: Modelos Teóricos e Abordagens. Contabilidade, Gestão e Governança, [S.I.], v. 14, n. 2, set. 2011. ISSN 1984-3925. Disponível em: https://www.revistacgg.org/contabil/article/view/314. Acesso em: 21 nov. 2019. 
ROSA, M. M. et al. A Lei de Acesso à Informação como Instrumento de Controle Social: Diagnóstico dos Municípios do Sul do Brasil à Luz do Artigo $8^{\circ}$ da Lei 12527/2011. NAVUS - Revista de Gestão e Tecnologia, v. 6, n. 1, p. 72-87, 2016. Disponível em: http://navus.sc.senac.br/index.php/navus/article/view/359. Acesso em: 22 nov. 2019.

SECCHIN, L. B. de M. Controle Social: transparência das políticas públicas e fomento ao exercício da cidadania. Revista da CGU, Brasília, v. 3, n. 5, p. 28-45, dez. 2008. Disponível em: https://repositorio.cgu.gov.br/handle/1/34431. Acesso em: 21 dez. 2019.

SILVA, T. E. da; GOMES, T. E.; CAVALCANTE, R. S. Acesso à Informação: notas de pesquisa. Informação \& Informação, [S.I.], v. 18, n. 2, p. 01-19, ago. 2013. ISSN 1981-8920. Disponível em: http://www.uel.br/revistas/uel/index.php/informacao/article/view/16125. Acesso em: 21 nov. 2019.

SILVA NETO, J. H. et al. Transparência Fiscal dos Municípios Mais Populosos do Estado de Pernambuco. Teoria e Prática em Administração. v. 9, n. 2, p. 64-76, 2019. Disponível em: https://periodicos.ufpb.br/ojs2/index.php/tpa/article/view/42178. Acesso em: 21 nov. 2019.

STIGLITZ, J. On liberty, the right to know, and public discourse: the role of transparency in public life. Washington, D.C.: World Bank Group, 1999. Disponível em: http://documents.worldbank.org/curated/en/436941546609601734/On-Liberty-the-Right-to-Know-andPublic-Discourse-The-Role-of-Transparency-in-Public-Life. Acesso em: 19 dez. 2019.

TRIVIÑOS, A. N. S.. Introdução à pesquisa em ciências sociais: a pesquisa qualitativa em educação. 16. reimp. São Paulo: Atlas, 2008.

VERGARA, S. C. Projetos e Relatórios de Pesquisa em Administração. 16. ed. São Paulo: Atlas, 2016.

VISENTINI, M.; SANTOS, M. Transparência na Gestão Pública Municipal Evidenciada nos Portais Eletrônicos dos Municípios do Conselho Regional de Desenvolvimento (Corede) das Missões/RS. Desenvolvimento em Questão, v. 17, n. 49, p. 158-175, 17 out. 2019. Disponível em:

https://www.revistas.unijui.edu.br/index.php/desenvolvimentoemquestao/article/view/8082. Acesso em: 21 nov. 2019.

W3C. Manual dos Dados Abertos: governo. Traduzido e adaptado de http://opendatamanual.org. W3C Brasil, 2011. Disponível em:

http://www.w3c.br/pub/Materiais/PublicacoesW3C/Manual_Dados_Abertos_WEB.pdf. Acesso em: 02 jan. 2020.

ZUCCOLOTTO, R.; TEIXEIRA, M. A. C.; RICCIO, E. L. Transparência: reposicionando o debate. Revista

Contemporânea de Contabilidade, v. 12, n. 25, p. 137-158, 2015. Disponível em: https://periodicos.ufsc.br/index.php/contabilidade/article/view/2175-8069.2015v12n25p137. Acesso em: 17 out. 2019. 